\title{
Patient considerations in the treatment of COPD: focus on the new combination inhaler fluticasone furoate/umeclidinium/vilanterol
}

This article was published in the following Dove Press journal:

Patient Preference and Adherence

\author{
Antonio Molino ${ }^{1, *}$ \\ Giovanna Calabrese ${ }^{1, *}$ \\ Mauro Maniscalco ${ }^{2}$ \\ 'Division of Pneumology, Department \\ of Respiratory Diseases, University \\ of Naples Federico II, AORN dei \\ Colli-Monaldi Hospital, Naples, Italy; \\ ${ }^{2}$ Pulmonary Rehabilitation Division, \\ ICS Maugeri SpA SB, Institute \\ of Telese Terme, Telese Terme, \\ Benevento, Italy \\ *These authors contributed equally \\ to this work
}

\begin{abstract}
The pharmacological treatment for stable COPD is based on the use of inhaled bronchodilators (long-acting muscarinic receptor antagonists and long-acting beta- 2 adrenoceptor agonists) and inhaled corticosteroids. The use of triple inhaled therapy is recommended to selected patients with COPD. Among the various inhaler combinations in triple therapy, a new combination by fluticasone furoate, umeclidinium, and vilanterol is available for COPD patients. Recently, a large clinical trial using this combination has been published, resulting in a reduction in exacerbation rate in COPD patients. Furthermore, this combination has demonstrated efficacy and safety, with a single administration a day, through a dry powder inhalator device, which has shown a good adherence and is a preference of the patient. This review focuses on the main characteristics of this inhaler combination evaluating the main clinical effects, the patients' adherence, and the safety.
\end{abstract}

Keywords: COPD, fluticasone, triple therapy, umeclidinium, vilanterol, rehabilitation

\section{Introduction}

COPD is a common, preventable, and treatable disease characterized by persistent respiratory symptoms and airflow limitation due to alveolar and/or airway abnormalities, usually caused by significant exposure to harmful particles or gases. ${ }^{1}$ COPD represents a major public health problem, being a disease with a prevalence of $10 \%$ in Europe. ${ }^{2,3}$ Epidemiological estimates related to this pathological condition also describe an expanding disease, which in recent decades has become the third leading cause of death in the world. The burden of the disease also depends on the presence of comorbidity and on the frequency of exacerbations. The latter is responsible for $50 \%-75 \%$ of the costs of the disease, especially if the patients then require hospitalization. ${ }^{1}$ Therefore, the attention is increased toward prevention campaigns focused on risk factor control, an early diagnosis, and an optimal treatment for both stable disease and exacerbations. In fact, the objectives of drug therapy aim at obtaining an optimal control of the current pathology, acting primarily on the reduction of symptoms, on the improvement of patients' performance status, and on the control of future risk, through a blockade of functional decline and prevention of exacerbations. These goals must be achieved by optimizing the therapy, in order to reduce the side effects, maximize the impact of treatment, and improve the compliance to the therapy. The latter represents a critical point in respiratory patients as it is approximately at $15 \% .{ }^{4}$ The choice of the device and the methods of administration also play a fundamental role. ${ }^{1}$
Correspondence: Mauro Maniscalco Via Bagni Vecchi I, 82037 Telese Terme, Benevento, Italy

$\mathrm{Tel} / \mathrm{fax}+39824909350$

Email mauromaniscalco@hotmail.com 
A focal point in the treatment of COPD is represented by the patients' adherence to the treatment, ${ }^{5}$ which in turn depends on the perception of the disease, the safety of the therapy, and the reduction of their symptoms. Furthermore, an important point for the patients' adherence to the treatment is the ease of use of the device or the number of the devices used for the therapy.

Several clinical trials take this into account and include methods of measuring patient satisfaction and the impact of therapy on quality of life.

This review will focus on the use of triple inhaled therapy with a particular focus on the once-a-day dry powder inhalator (DPI) fixed-dose combination of fluticasone furoate (FF), umeclidinium bromide (UMEC), and vilanterol trifenatate (VI).

\section{The role of triple inhaled therapy in COPD}

The inhaled therapy used in COPD consists in heterogeneous pharmacological classes that can act on the lungs by different mechanisms of action, determining a bronchodilation, and therefore the improvement of many functional parameters. In this way, they can have important repercussions on the patients' state of health, on their performance status, and on the quality of life. ${ }^{6}$ Moreover, through inhaled administration, it is possible to reduce the side effects given by systemic administration, even if these events cannot be completely eliminated. The categories of drugs referred to in this case are mainly antimuscarinic agents, beta- 2 agonists, and corticosteroids.

Antimuscarinic agents act at the pulmonary level mainly by antagonizing the acetylcholine binding at the postsynaptic level on the M3 receptor and at the presynaptic level on the M2 receptor. They directly regulate the bronchial tone at the pulmonary level and at the systemic level, act on glands and epithelia, regulating the production and the clearance of mucus, the frequency of ciliary beating, and in general they can carry out a regulatory action on inflammation. The differences between the various agents belonging to this pharmacological category are related to the action selectivity, the time of action, and the speed of action. ${ }^{7}$

Beta-2 agonists are an important pharmacological category for the treatment of bronchoconstriction. They act by binding to the beta-2 adrenergic receptor, which ultimately determines bronchodilation through the production of cAMP. Many molecules for this pharmacological category have been developed over the years, with some molecules focused on speed and duration of action, while others on selective receptor and, therefore, for efficacy and safety. ${ }^{8}$ In addition to the bronchodilator effect, they may also have other functions at the pulmonary level, such as regulation of the inflammatory activity and inhibition of cholinergic action. This, therefore, is a synergistic effect with respect to antimuscarinic agents and a synergistic action also of glucocorticoids action.

Inhaled glucocorticoids (ICS) are the most important regulators of the inflammatory state of the airways. The mechanisms of action of glucocorticoids are very complex: they can regulate through the binding to specific receptors in gene transcription of many elements of inflammation, suppressing proinflammatory genes, and activating antiinflammatory genes instead. In this way, they can reduce the numbers of inflammatory cells at cellular level, including eosinophils, T-lymphocytes, mast cells, and dendritic cells. ${ }^{9}$ These three classes of drugs act among them with synergic action by increasing the receptor expression and binding, by increasing the antiinflammatory effect, and by modulating the mediator release (Figure 1). ${ }^{10,11}$

According to the GOLD guidelines, the most appropriate therapeutic choice for a COPD patient begins with the classification of his/her disease severity. The identification of subgroup to which the patient belongs is important because these specific recommendations can guide the physician to decide whether to start with an inhaled monotherapy or eventually move to a combination therapy of long acting beta agonist (LABA) and long acting muscarinic antagonist (LAMA).

In patients characterized by the most severe functional and symptomatic alteration and by the highest risk of exacerbations in groups $\mathrm{D}$ and $\mathrm{C}$, the use of a triple combination LAMA, LABA, and ICS may be recommended. ${ }^{1}$

The treatment of patients with COPD should be constructed based on patients' spirometric values, symptoms, and perception of the patients' disease, as well as on the frequency of exacerbations. Therefore, patients in stage A, less symptomatic, with a pathology of lesser severity and with less probability of exacerbations, should start the treatment with a single bronchodilator. In group B, similar to group A in terms of clinical-instrumental features, but with more pronounced symptoms, patients can benefit from a long-acting bronchodilator, and in case of persistence of symptoms, from the combination of two long-acting bronchodilators. ${ }^{1}$

In the case of greater flow limitations and greater possibility of COPD exacerbations, it is possible to introduce an inhaled ICS therapy, either in combination with another bronchodilator if the patient is not very symptomatic, or in triple therapy if the patient is strongly symptomatic.

However, while the central role of bronchodilators in COPD is clearly established, controversy exists regarding the 


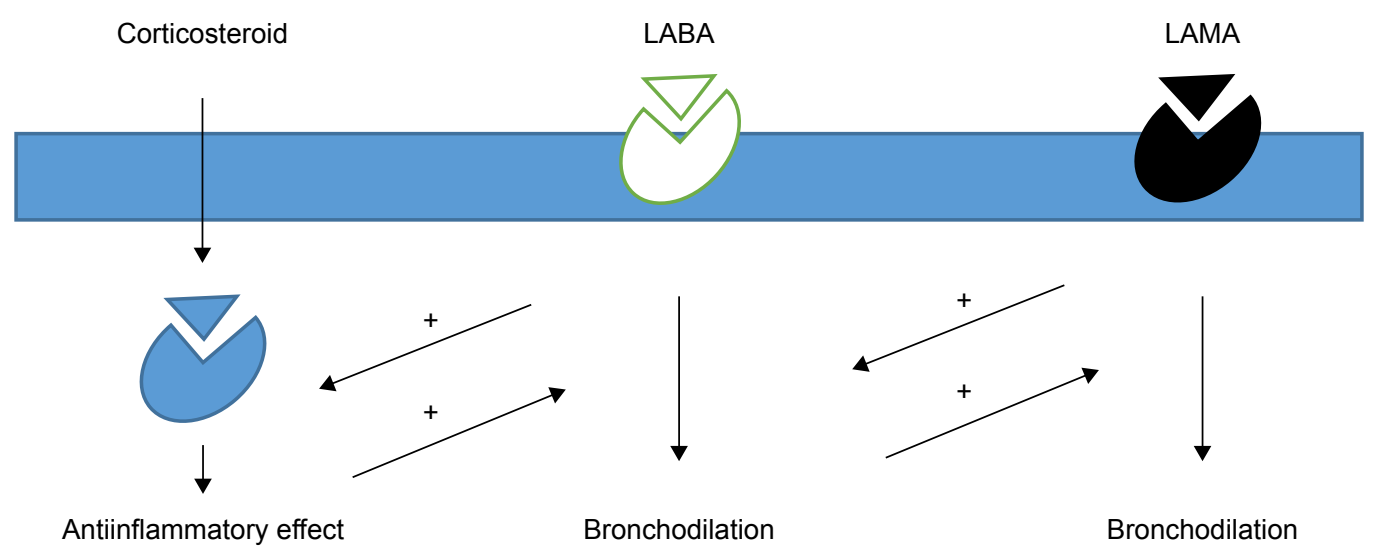

Figure I Schematic representation of synergic mechanisms of antimuscarinic agents, beta-2 agonists, and inhaled corticosteroids. Abbreviations: LABA, long acting beta agonist; LAMA, long acting muscarinic antagonist.

use of ICS in COPD. ${ }^{12}$ In fact, the use of ICS may increase the risk of developing respiratory infections such as pneumonia. Furthermore, a retrospective general practice cohort study in the United Kingdom has shown that the rate of exacerbations requiring hospitalizations did not change, notwithstanding the increased number of prescriptions for LABA plus ICS combinations. $^{13}$

The identification of patients with an asthmatic component or the identification of elevated levels of eosinophils could in fact identify a group of patients more sensitive to this therapy. However, the use of a triple therapy is recommended only in patients of group $\mathrm{C}$ or $\mathrm{D}$, which despite the combination therapy of LABA and LAMA still show severe symptoms or frequent exacerbations. ${ }^{1}$

Clinical studies dedicated to the evaluation of the efficacy and safety of triple therapy have not reached an absolute agreement.

Many clinical studies have shown that the LABA/LAMA/ ICS combination is able to demonstrate a significant improvement in the functional parameters of patients with moderate to severe COPD, compared with LAMA alone. ${ }^{14-18}$ These studies have shown an improvement in $\mathrm{FEV}_{1}$ and other physiological and symptomatological parameters, after the transition to triple therapy, such as the values of lung volumes or airway conductance, with statistically significant differences. The same studies did not give consistent data regarding exacerbations. In some cases, ${ }^{14,19,20}$ the exacerbations seemed significantly reduced, while in other comparative studies no significant differences were observed. ${ }^{16,18,21}$ These data could also be influenced by the criteria for defining and identifying the exacerbation, the difference in the inclusion criteria, and the duration of the follow-up. The effect on COPD exacerbations was studied on a Scottish cohort by Manoharan et al, ${ }^{22}$ which demonstrated a reduction in exacerbations and related hospitalizations and a reduction in overall mortality when patients are treated with triple therapy or with ICS/LAMA combination compared with the ICS combination with LABA alone. In a deep analysis of the individual causes of death, only the triple therapy was recognized to be able to significantly reduce the cardiovascular mortality. ${ }^{22}$

However, when triple therapy is prescribed in carefully selected patients, univocal data emerge: a statistically significant improvement in the quality of life, a lower use of the drug when needed, and an improvement in symptoms of dyspnea and pulmonary function when compared with LAMA alone. ${ }^{14-18}$ Less evidence is available in the literature on the comparison of the triple therapy to the therapy with LAMA/LABA, often with discordant results. A meta-analysis has shown that the combination indacaterol/tiotropium can have effects on lung function and quality of life overlapping the triple therapy. ${ }^{23}$ A comparison study of the inhaled triple therapy versus the tiotropium/salmeterol combination demonstrates a risk of overlapping exacerbations between patients who continue and those who stop ICS, even if in the latter a decline in the spirometric parameters is observed in the final stages of the study. ${ }^{24}$

The appropriateness of prescription is another point which has to be considered. In fact, the lack of a well-defined indication for triple inhaled therapy for COPD results in differences in real-life prescription patterns. Accordingly, Brusselle et al has shown in the UK, a prescription of triple therapy not always in accordance with the recommendations listed in the guidelines, observed patients with COPD GOLD $\mathrm{A}$ and $\mathrm{B}$ in treatment with triple therapy. ${ }^{25}$ Di Marco et al has shown a poor prescriptive appropriateness even in Italy, also highlights a low demand for spirometry and specialist examinations by the general practitioner. ${ }^{26}$ These data are not of little importance if we consider that this therapy is not without side effects, attributable in particular to the chronic use of corticosteroids. ${ }^{25,27-29}$ 


\section{The new combination of FF/ umeclidinium/vilanterol inhaler}

Among the various inhaler combinations in triple therapy, a new combination is given by FF/UMEC/VI.

FF is a potent corticosteroid with antiinflammatory action that acts by preserving epithelial integrity and reducing epithelial permeability in response to protease-induced cell damage or resulting from mechanical damaging stimuli. ${ }^{18}$

UMEC acts for competitive antagonism on muscarinic receptors. It has a very strong bond with the M3 receptor comparable to that of tiotropium, with a speed of dissociation from the $\mathrm{M} 3$ receptor slower than that from the $\mathrm{M} 2$ receptor. The time required to reach the maximum concentration is between 5 and 15 minutes, ensuring a remarkable speed of action. This kinetics results in a long-lasting bronchodilation and, therefore, in the possibility of a single daily dose. ${ }^{30}$

VI is a powerful and selective beta-2 agonist, which was developed in combination with FF in the treatment for asthma and with UMEC for COPD. It represents a good rapidity of action, since after its intake, it reaches its maximum concentration after about 10 minutes. It also has a minimal systemic absorption and therefore an optimal safety profile. VI is metabolized into compounds that continue to have an action, resulting in a long duration of action. ${ }^{31}$ In some preclinical models, VI showed a significantly faster action of onset versus that of salmeterol and a longer duration of action than salmeterol and formoterol. ${ }^{32}$

The efficacy of the combination between UMEC and VI has already been studied after the introduction of dual bronchodilation. In fact, many studies have shown the efficacy of this combination ${ }^{33-35}$ and a good safety profile. ${ }^{33}$ The UMEC/VI combination has shown a positive influence on the quality of life of the treated patients. ${ }^{36}$

\section{Symptoms and functional parameters}

The combination of FF/UMEC/VI gave positive results when the effects were studied using two separate DPIs. ${ }^{37}$ The same combination of $\mathrm{FF} / \mathrm{UMEC} / \mathrm{VI}$ gave positive results also when compared with other ICS + LABA combinations in improving lung function and health status, for the first time in the FULFIL study, in which the drugs are administered only once a day from the same device. ${ }^{38}$

The FULFIL study was a 24-week, randomized, doubleblind, double-dummy, parallel-group, multicenter study, which involved 1,810 patients with moderate or severe COPD and with a history of at least two or more moderate or one severe exacerbation (requiring hospitalization) in the previous 12 months after recruitment. The recruited patients also had a significant symptomatology, demonstrated by a COPD assessment test (CAT) score of $\geq 10$ at the entrance to the study. The patients were divided into two groups, one of which received the triple FF/UMEC/VI therapy and the other with budesonide/formoterol. This study showed an improvement of $\mathrm{FEV}_{1}$ in the first arm compared with the ICS + LABA combination. In fact, an increase of $142 \mathrm{~mL}$ was observed at $\mathrm{FEV}_{1}$ at the end of 24 weeks in the study arm which included patients who had received the triple therapy, compared with a worsening of $\mathrm{FEV}_{1}$, of about $29 \mathrm{~mL}$, in those who had received the ICS + LABA combination. ${ }^{38}$

The FULFIL study also showed an improvement in the patients' symptomatology, demonstrated by a reduction of 6.6 points in the result of the St George respiratory questionnaire (SGRQ) test at the end of the 24 weeks of observation in the first arm, and of 4.3 points in the second arm. The beneficial effects of triple therapy have also been evident in terms of reduced use of the drug when needed.

The advantages shown by the FF/UMEC/VI combination have also been confirmed by comparing FF/VI with UMEC using different devices. Bremner et al has shown, in a Phase III, multicenter, randomized, double-blind, parallelgroup study, that the inhalation of the triple therapy with a single device is not inferior to the inhalation of the same therapy if administered in two different devices. ${ }^{39}$

An important response to the use of FF/UMEC/VI combination has been given by the IMPACT trial, a 52-week Phase III, randomized, double-blind, three-arm, parallelgroup, global multicenter study, which was completed in July 2017 and published in April 2018. ${ }^{40}$

In this study, the primary outcome was to compare the rate of moderate and severe exacerbations between singleinhaler FF/UMEC/VI and single-inhaler FF/VI or UMEC/VI in $>10,000$ patients affected by severe-to-very severe COPD. The comparison of single-inhaler triple ICS/LABA/LAMA therapy versus single-inhaler dual LAMA/LABA therapy is of particular relevance, as the lack of similar studies represents an unmet need in pharmacological treatment of COPD.

Patients completed an electronic diary each morning to record their symptoms. The severity of an exacerbation was defined according to the treatment. The rate of moderate or severe exacerbations was significantly lower with the combination of FF, UMEC, and VI (0.91 per year) than with $\mathrm{FF} / \mathrm{VI}$ (1.07 per year) or UMEC/VI (1.21 per year). ${ }^{40}$

For the spirometric outcome of the mean change from baseline in trough $\mathrm{FEV}_{1}$, the difference between the triple therapy and the FF/VI groups was $97 \mathrm{~mL}$ (95\% CI, 85-109; $P<0.001$ ), and the difference between the triple therapy 
and the UMEC/VI groups was $54 \mathrm{~mL}(95 \% \mathrm{CI}, 39-69$; $P<0.001)$.

\section{Quality of life}

Several clinical trials have been performed to assess the patients' general state of health and disease perception including the quality of life (HRQoL) $)^{41,42}$ using various questionnaires. One of the most complete questionnaires is the SGRQ, a questionnaire used for both asthma and COPD. ${ }^{43}$ The SGRQ is the tool used to discriminate between patient differences and to assess changes in perception in the same patient over time. Another questionnaire, the CAT, consists in fact only eight questions, whose answer can be easily identified on a scale from 1 to 5 , the higher the number, the more serious the condition of the patient in relation to that disorder. ${ }^{44}$ This test was used in the FULFIL study to evaluate the patients' symptoms at the entrance to the study: being required that the patients were symptomatic, one of the inclusion criteria provided a CAT score $\geq 10$.

The FULFIL study demonstrated a statistically significant improvement in HRQoL. At the entrance to the study, the patients were selected according to CAT. Subsequently, the BDI (Basic Dyspnea Index) was administered as an interviewer-administered rating of severity of dyspnea at a single state. On subsequent visits, the patients' health status was investigated through the SGRQ and the Transition Dyspnea Index, which measure changes in dyspnea severity from the baseline, as established by the BDI. The patients only carried out the CAT again at the final visit. At the end of the FULFIL study, an improvement in HRQoL was observed in both arms of the study at week 24 , but the mean changes from baseline in the triple therapy group were statistically higher than those in the dual therapy group, if they evaluated the total scores of both the CAT and the SGRQ. ${ }^{45}$ The SGRQ score, in fact, varies by 2.2 points in the group treated with triple therapy compared with the group treated with ICS + LABA and the CAT score shows a difference of 0.9 points in the improvement sense in the first group compared with the second at the end of the study.

The FULFIL study also demonstrated a statistically significant improvement in the triple therapy group compared with the arm of ICS + LABA in functional limitation and a socioeconomic benefit assessed by administering the health care resource utilization questionnaire, a tool designed to estimate the use of economic resources in the medical field, to patients. ${ }^{46}$

The total cost of patients in triple treatment is greater at 24 weeks, but it was lower than the second arm if instead the observation is prolonged to 52 weeks. These socioeconomic evaluations should be reassessed in light of the fact that these findings were made in the FULFIL study only in the UK and that the economic benefit was demonstrated only at 52 weeks. ${ }^{28}$

The effect of single-inhaler FF/UMEC/VI versus singleinhaler FF/VI or UMEC/VI in COPD on changes in SGRQ total score has also been a secondary outcome of the IMPACT trial. ${ }^{40}$ In this study, the patients with triple therapy presented an improvement in mean change from baseline in the SGRQ total score when compared with the FF/VI and UMEC/VI groups.

\section{Adherence to the treatment}

Medication adherence in patients with COPD, like with all chronic disorders, is complex, although it is crucial for the best outcomes. Therapeutic adherence can be influenced by several factors relating to disease severity, the doctor-patient relationship, the socioeconomic factors, and the therapy itself. In particular, this includes the frequency of administration, the speed of action of the drug, and the manageability of the device. ${ }^{47-49}$

It is evident that a simpler therapeutic scheme will guarantee a better adherence of the patient, especially in COPD patients, which more frequently affect elder patients, often suffering from other comorbidities and therefore assuming numerous drugs. In these patients, it is suggested to simplify the treatment. Indeed, many studies have shown that patients are more compliant with once daily administration than treatment regimens twice or three times a day ${ }^{50,51}$ In a large retrospective study (55,076 COPD patients), medication adherence strongly correlated with dosing frequency. ${ }^{52}$ Furthermore, patients using multiple inhalers experienced more exacerbations..$^{53}$

In COPD patients, the poor adherence to the treatment may depend on the difficulty or insufficient training to the device. ${ }^{54,55}$ The choice of the most appropriate device also depends on the patient's clinical condition. The devices currently in use are varied. In particular, there are metered-dose inhaler (MDI) devices on one side and DPI devices on the other. The first are spray or MDI aerosols predosed in pressurized cans, characterized by a high delivery speed, which increases the oropharyngeal deposition and therefore the frequency of local side effects and provide a good coordination of the patient to properly perform the inhalation. DPI devices are powder dispensers, which do not require coordination by the patient, do not contain propellants, and have reproducibility of the delivered dose. The disadvantage is represented 
by the need to apply an inhalation effort sufficient to inhale the powder from the device and the possibility that it will trigger the cough. DPI devices can be monodose or multidose. Next to these, soft mist inhaler and ultrasonic or compressed air nebulizers can be added. Although some studies have shown greater adherence to treatment with MDIs compared with DPIs, ${ }^{56}$ other studies demonstrate greater efficacy of administration in DPI devices or an equal effectiveness between the two types of devices.

Ramadan and Sarkis have shown that $\sim 70 \%$ of patients using DPI perform therapy correctly compared with about $40 \%$ of those using MDI. ${ }^{57}$ In this study, $~ 81.4 \%$ of MDI users identify the coordination between container pressure and inhalation as the most difficult passage. These results are probably explained by the less complex administration (no coordination is needed) with DPI. The discrepancy between the various studies is an expression that there is no ideal inhaler, but we must choose the most appropriate device to the characteristics of the patient to be treated and the drug to be administered. All the devices present advantages and disadvantages. The common errors for both DPI and MDI were expiration before the dose, apnea after the dose, waiting between two consecutive doses, and finally gargle after a dose of corticosteroids. ${ }^{57,58}$

However, the ideal device should have a low internal resistance, allow a good reproducibility of the dose, generate a high fraction of fine particles, and, therefore, determine a high pulmonary deposition. At the same time, a good device should be easy to use, have a system for checking the dose inhalation and a simple system for the counting of doses, and should be resistant to the action of any external agents, such as humidity or trauma.

The ELLIPTA device, which is the tool to administrate FF/UMEC/VI, is a device with a dose counting system and a medium-low resistance system, which does not dispense preestablished suspensions, but determines the mixing of the doses of the different drugs at the time of the activation of the flow from the patient. It does not have any humidity control systems, so there is a deadline after 6 weeks. ${ }^{59,60}$ Several studies have demonstrated the efficacy of this device (Table 1). Svedsater et al have reported a positive opinion with the use of ELLIPTA in patients with asthma and COPD already in treatment with other devices. This was due to the lowest number of steps to be taken in order to inhale the drug, the compactness of the device and the size, the ease in remembering the operation, the size of the mouthpiece, and other features. ${ }^{61}$ This was confirmed by van der Palen et $\mathrm{al}^{62}$ who showed fewer errors in patients using ELLIPTA compared with naive patients who used other devices.

ELLIPTA was compared with both Diskus ${ }^{63}$ and Handihaler devices. ${ }^{64}$ In both the studies, the patients expressed preference for ELLIPTA regarding the ease of use and therefore the characteristics of the device itself. Accordingly, Komase et al reported similar results in a Japanese population, demonstrating a preference of patients for ELLIPTA in particular, for ease of use, number of steps needed, and time taken to operate the inhaler. ${ }^{65}$

Several recent randomized controlled trials evaluated the efficacy and safety of triple ICS/LABA/LAMA therapy using a single fixed-dose combined inhaler for patients with COPD. ${ }^{19,20}$

Bremner showed that FF/UMEC/VI administered with only one inhaler was not inferior to FF/VI plus UMEC administered at the same dosages but in two separate devices, in terms of improvement of $\mathrm{FEV}_{1}$. His findings confirm that triple therapy with a single inhaler with FF/UMEC/VI offers similar efficacy, health, and quality of life, such as the triple therapy administered with two separate inhalers. ${ }^{66}$

At the final study visit, patients were also asked to express a preference regarding the device: among patients

Table I Studies comparing ELLIPTA with other devices

\begin{tabular}{|c|c|c|c|c|}
\hline Study & Year & $\begin{array}{l}\text { Number } \\
\text { of COPD } \\
\text { patients }\end{array}$ & Primary endpoint & Results \\
\hline Svedsater et $\mathrm{al}^{61}$ & 2013 & 42 & $\begin{array}{l}\text { Comparison among ELLIPTA and other devices } \\
\text { about their satisfaction with various attributes of } \\
\text { the inhalers }\end{array}$ & $\begin{array}{l}\text { The ELLIPTA was associated with high patient } \\
\text { satisfaction and was preferred to other inhalers when } \\
\text { participants with asthma and COPD were interviewed }\end{array}$ \\
\hline Komase et al ${ }^{65}$ & 2014 & 150 & $\begin{array}{l}\text { Preference for ease of use between ELLIPTA and } \\
\text { the Breezhaler device }\end{array}$ & $\begin{array}{l}\text { The ELLIPTA was preferred for ease of use and } \\
\text { number of steps }\end{array}$ \\
\hline van der Palen et $\mathrm{al}^{62}$ & 2016 & 567 & $\begin{array}{l}\text { Errors in the use of the ELLIPTA compared to } \\
\text { other devices }\end{array}$ & $\begin{array}{l}\text { Fewer errors in patients using ELLIPTA in naive } \\
\text { patients }\end{array}$ \\
\hline Yun Kirby et al ${ }^{63}$ & 2016 & 287 & $\begin{array}{l}\text { Inhale preference based on size of the numbers on } \\
\text { the dose counter }\end{array}$ & $\begin{array}{l}\text { More patients preferred five specific inhaler attributes } \\
\text { of the ELLIPTA when compared with Diskus }\end{array}$ \\
\hline Collison et $\mathrm{al}^{64}$ & 2018 & 214 & $\begin{array}{l}\text { Preference between ELLIPTA and Handihaler based } \\
\text { on the number of steps needed to use the inhaler }\end{array}$ & Preference for ELLIPTA \\
\hline
\end{tabular}


who expressed a preference, there was a greater preference for the ELLIPTA inhaler than the Turbuhaler. ${ }^{45}$

\section{Safety}

Pharmacokinetic studies do not suggest clinically relevant pharmacokinetic differences between FF, UMEC, or VI intake when given as a triple therapy compared to separate $\mathrm{FF} / \mathrm{VI}$ and UMEC/VI. It can, therefore, be assumed that the lung dose and safety of all three agents, delivered by a single inhaler, are similar to those of the approved FF/VI and UMEC/VI therapies. ${ }^{67}$

Two randomized trials were conducted to study the safety and efficacy of UMEC added to FF/VI. ${ }^{37,67}$ When the use of $\mathrm{FF} / \mathrm{VI}$ or UMEC was compared with the triple combination of $\mathrm{UMEC} / \mathrm{FF} / \mathrm{VI}$, no major adverse or side effects were observed, and the therapy was generally well tolerated. In fact, few adverse events were observed, and the experimenters did not consider that they were to be attributed to the therapy in progress. The most common side effects reported include nasopharyngitis, headache, and back pain. ${ }^{38}$ In both studies on this combination, totally, six deaths were reported but were not considered to be related to study treatment. Only one serious adverse event of diabetes mellitus was reported, which was shown to be a previously undiagnosed case of type 2 diabetes mellitus..$^{37,67}$

\section{Conclusion}

The inhaler triple therapy with ICS/LAMA/LABA has demonstrated efficacy and safety in clinical studies, obviously with a variability based on the endpoint considered. The triple therapy has in fact shown efficacy in terms of respiratory function and quality of life.

An important point among the considerations regarding the triple therapy is the identification of the subgroup of COPD patients deserving to be treated with this protocol. Therefore, a correct diagnosis and stratification of the disease's severity are needed. In other terms, it is necessary and fundamental to identify the group of patients that can best respond to the combined treatment with ICS/LAMA/LABA.

Currently, several inhaler combinations in triple therapy are being produced. In particular, the FF/UMEC/VI combination has demonstrated efficacy and safety, with a single administration a day, through a DPI device, especially after the recent publication of IMPACT study which has added new data.

The inhaler combination FF/UMEC/VI has shown a good patient adherence and preference from patients, probably linked to a greater easy handling and ease of use of simultaneous administration of three drugs, offering the potential for better compliance and results in patients with advanced COPD. Obviously, we think that an adequate choice of treatment for the patient is fundamental even for this combination.

\section{Disclosure}

The authors report no conflicts of interest in this work.

\section{References}

1. Vestbo J, Hurd SS, Agusti AG, et al. Global strategy for the diagnosis, management, and prevention of chronic obstructive pulmonary disease: GOLD executive summary. Am J Respir Crit Care Med. 2013; 187(4):347-365.

2. Miravitlles M, Soriano JB, Garcia-Rio F, et al. Prevalence of COPD in Spain: impact of undiagnosed COPD on quality of life and daily life activities. Thorax. 2009;64(10):863-868.

3. Lopez-Campos JL, Tan W, Soriano JB. Global burden of COPD. Respirology. 2016;21(1):14-23.

4. Sanduzzi A, Balbo P, Candoli P, et al. COPD: adherence to therapy. Multidiscip Respir Med. 2014;9(1):60.

5. Chrystyn H, Small M, Milligan G, Higgins V, Gil EG, Estruch J. Impact of patients' satisfaction with their inhalers on treatment compliance and health status in COPD. Respir Med. 2014;108(2):358-365.

6. Fromer L, Goodwin E, Walsh J. Customizing inhaled therapy to meet the needs of COPD patients. Postgrad Med. 2010;122(2):83-93.

7. Buels KS, Fryer AD. Muscarinic receptor antagonists: effects on pulmonary function. Handb Exp Pharmacol. 2012;208:317-341.

8. Corsico A, Fulgoni P, Beccaria M, et al. Effects of exercise and beta 2-agonists on lung function in chronic obstructive pulmonary disease. J Appl Physiol (1985). 2002;93(6):2053-2058.

9. Barnes PJ. Inhaled corticosteroids. Pharmaceuticals (Basel). 2010; 3(3):514-540.

10. Calzetta L, Matera MG, Cazzola M. Pharmacological interaction between LABAs and LAMAs in the airways: optimizing synergy. Eur J Pharmacol. 2015;761:168-173.

11. Currie GP, Lipworth BJ. Pharmacological management-inhaled treatment. BMJ. 2006;332(7555):1439-1441.

12. Barnes PJ. Inhaled corticosteroids in COPD: a controversy. Respiration 2010;80(2):89-95.

13. Harries TH, Seed PT, Jones S, Schofield P, White P. Chronic obstructive pulmonary disease hospital admissions and drugs-unexpected positive associations: a retrospective general practice cohort study. NPJ Prim Care Respir Med. 2014;24:14006.

14. Lee SD, Xie CM, Yunus F, et al. Efficacy and tolerability of budesonide/ formoterol added to tiotropium compared with tiotropium alone in patients with severe or very severe COPD: a randomized, multicentre study in East Asia. Respirology. 2016;21(1):119-127.

15. Singh D, Brooks J, Hagan G, Cahn A, O'Connor BJ. Superiority of "triple" therapy with salmeterol/fluticasone propionate and tiotropium bromide versus individual components in moderate to severe COPD. Thorax. 2008;63(7):592-598.

16. Jung KS, Park HY, Park SY, et al; Korea Chronic Obstructive Pulmonary Disease study group. Comparison of tiotropium plus fluticasone propionate/salmeterol with tiotropium in COPD: a randomized controlled study. Respir Med. 2012;106(3):382-389.

17. Liu Y, Shi H, Sun X, et al. Benefits of adding fluticasone propionate/ salmeterol to tiotropium in COPD: a meta-analysis. Eur J Intern Med. 2014;25(5):491-495.

18. Malerba M, Nardin M, Santini G, Mores N, Radaeli A, Montuschi P. Single-inhaler triple therapy utilizing the once-daily combination of fluticasone furoate, umeclidinium and vilanterol in the management of COPD: the current evidence base and future prospects. Ther $A d v$ Respir Dis. 2018;12:1753466618760779. 
19. Vestbo J, Papi A, Corradi M, et al. Single inhaler extrafine triple therapy versus long-acting muscarinic antagonist therapy for chronic obstructive pulmonary disease (TRINITY): a double-blind, parallel group, randomised controlled trial. Lancet. 2017;389(10082):1919-1929.

20. Singh D, Papi A, Corradi M, et al. Single inhaler triple therapy versus inhaled corticosteroid plus long-acting beta2-agonist therapy for chronic obstructive pulmonary disease (TRILOGY): a double-blind, parallel group, randomised controlled trial. Lancet. 2016;388(10048):963-973.

21. Aaron SD, Vandemheen KL, Fergusson D, et al; Canadian Thoracic Society/Canadian Respiratory Clinical Research Consortium. Tiotropium in combination with placebo, salmeterol, or fluticasone-salmeterol for treatment of chronic obstructive pulmonary disease: a randomized trial. Ann Intern Med. 2007;146(8):545-555.

22. Manoharan A, Short PM, Anderson WJ, Lipworth BJ. Impact of longacting bronchodilators and exposure to inhaled corticosteroids on mortality in COPD: a real-life retrospective cohort study. Lung. 2014; 192(5):649-652.

23. Kraemer M, Ellis A, Baldwin M, Jansen JP, Capkun-Niggli G, Cope S. PRS5 dual bronchodilation with indacaterol and tiotropium in combination versus triple therapy, fixed-dose combinations, and monotherapy in COPD. A network meta-analysis of $\mathrm{FEV}_{1}$. Value Health. 2012; 15(7):A560.

24. Magnussen H, Disse B, Rodriguez-Roisin R, et al; WISDOM Investigators. Withdrawal of inhaled glucocorticoids and exacerbations of COPD. N Engl J Med. 2014;371(14):1285-1294.

25. Brusselle G, Price D, Gruffydd-Jones K, et al. The inevitable drift to triple therapy in COPD: an analysis of prescribing pathways in the UK. Int J Chron Obstruct Pulmon Dis. 2015;10:2207-2217.

26. Di Marco F, Santus P, Terraneo S, et al. Characteristics of newly diagnosed COPD patients treated with triple inhaled therapy by general practitioners: a real world Italian study. NPJ Prim Care Respir Med. 2017;27(1):51.

27. Kew KM, Seniukovich A. Inhaled steroids and risk of pneumonia for chronic obstructive pulmonary disease. Cochrane Database Syst Rev. 2014;3:CD010115.

28. Yang IA, Clarke MS, Sim EH, Fong KM. Inhaled corticosteroids for stable chronic obstructive pulmonary disease. Cochrane Database Syst Rev. 2012;7:CD002991.

29. Cho KH, Kim YS, Linton JA, Nam CM, Choi Y, Park EC. Effects of inhaled corticosteroids/long-acting agonists in a single inhaler versus inhaled corticosteroids alone on all-cause mortality, pneumonia, and fracture in chronic obstructive pulmonary disease: a nationwide cohort study 2002-2013. Respir Med. 2017;130:75-84.

30. Babu KS, Morjaria JB. Umeclidinium in chronic obstructive pulmonary disease: latest evidence and place in therapy. Ther Adv Chronic Dis. 2017;8(4-5):81-91.

31. Malerba M, Morjaria JB, Radaeli A. Differential pharmacology and clinical utility of emerging combination treatments in the management of COPD-role of umeclidinium/vilanterol. Int J Chron Obstruct Pulmon Dis. 2014;9:687-695.

32. Hanania NA, Feldman G, Zachgo W, et al. The efficacy and safety of the novel long-acting beta2 agonist vilanterol in patients with COPD: a randomized placebo-controlled trial. Chest. 2012;142(1):119-127.

33. Zheng J, Zhong N, Newlands A, Church A, Goh AH. Efficacy and safety of once-daily inhaled umeclidinium/vilanterol in Asian patients with COPD: results from a randomized, placebo-controlled study. Int J Chron Obstruct Pulmon Dis. 2015;10:1753-1767.

34. Cazzola M, Segreti A, Matera MG. New developments in the combination treatment of COPD: focus on umeclidinium/vilanterol. Drug Des Devel Ther. 2013;7:1201-1208.

35. Kerwin EM, Kalberg CJ, Galkin DV, et al. Umeclidinium/vilanterol as step-up therapy from tiotropium in patients with moderate COPD: a randomized, parallel-group, 12-week study. Int J Chron Obstruct Pulmon Dis. 2017;12:745-755.

36. Siler TM, Donald AC, O'Dell D, Church A, Fahy WA. A randomized, parallel-group study to evaluate the efficacy of umeclidinium/vilanterol 62.5/25 mug on health-related quality of life in patients with COPD. Int J Chron Obstruct Pulmon Dis. 2016;11:971-979.
37. Siler TM, Kerwin E, Sousa AR, Donald A, Ali R, Church A. Efficacy and safety of umeclidinium added to fluticasone furoate/vilanterol in chronic obstructive pulmonary disease: results of two randomized studies. Respir Med. 2015;109(9):1155-1163.

38. Lipson DA, Barnacle H, Birk R, et al. FULFIL trial: once-daily triple therapy for patients with chronic obstructive pulmonary disease. Am J Respir Crit Care Med. 2017;196(4):438-446.

39. Bremner PR, Birk R, Brealey N, Ismaila AS, Zhu CQ, Lipson DA. Single-inhaler fluticasone furoate/umeclidinium/vilanterol versus fluticasone furoate/vilanterol plus umeclidinium using two inhalers for chronic obstructive pulmonary disease: a randomized non-inferiority study. Respir Res. 2018;19(1):19.

40. Lipson DA, Barnhart F, Brealey N, et al; IMPACT Investigators. Oncedaily single-inhaler triple versus dual therapy in patients with COPD. N Engl J Med. 2018;378(18):1671-1680.

41. Jones PW, Quirk FH, Baveystock CM, Littlejohns P. A self-complete measure of health status for chronic airflow limitation. The St. George's respiratory questionnaire. Am Rev Respir Dis. 1992;145(6): 1321-1327.

42. Katsura H, Yamada K, Kida K. Usefulness of a linear analog scale questionnaire to measure health-related quality of life in elderly patients with chronic obstructive pulmonary disease. J Am Geriatr Soc. 2003; 51(8):1131-1135.

43. Barr JT, Schumacher GE, Freeman S, LeMoine M, Bakst AW, Jones PW. American translation, modification, and validation of the St. George's respiratory questionnaire. Clin Ther. 2000;22(9):1121-1145.

44. Gupta N, Pinto LM, Morogan A, Bourbeau J. The COPD assessment test: a systematic review. Eur Respir J. 2014;44(4):873-884.

45. Tabberer M, Lomas DA, Birk R, et al. Once-daily triple therapy in patients with COPD: patient-reported symptoms and quality of life. Adv Ther. 2018;35(1):56-71.

46. Ismaila AS, Birk R, Shah D, et al. Once-daily triple therapy in patients with advanced COPD: healthcare resource utilization data and associated costs from the FULFIL trial. Adv Ther. 2017;34(9): 2163-2172.

47. Albertson TE, Harper R, Murin S, Sandrock C. Patient considerations in the treatment of COPD: focus on the new combination inhaler umeclidinium/vilanterol. Patient Prefer Adherence. 2015;9:235-242.

48. Libby AM, Fish DN, Hosokawa PW, et al. Patient-level medication regimen complexity across populations with chronic disease. Clin Ther. 2013;35(4):385.e1-398.e1.

49. Carr-Lopez SM, Shek A, Lastimosa J, et al. Medication adherence behaviors of medicare beneficiaries. Patient Prefer Adherence. 2014;8: $1277-1284$.

50. Saini SD, Schoenfeld P, Kaulback K, Dubinsky MC. Effect of medication dosing frequency on adherence in chronic diseases. Am J Manag Care. 2009;15(6):e22-e33.

51. Coleman CI, Limone B, Sobieraj DM, et al. Dosing frequency and medication adherence in chronic disease. J Manag Care Pharm. 2012; 18(7):527-539.

52. Toy EL, Beaulieu NU, McHale JM, et al. Treatment of COPD: relationships between daily dosing frequency, adherence, resource use, and costs. Respir Med. 2011;105(3):435-441.

53. Yu AP, Guerin A, de Leon DP, et al. Clinical and economic outcomes of multiple versus single long-acting inhalers in COPD. Respir Med. 2011;105(12):1861-1871

54. Lavorini F. Inhaled drug delivery in the hands of the patient. J Aerosol Med Pulm Drug Deliv. 2014;27(6):414-418.

55. Melani AS. Inhalatory therapy training: a priority challenge for the physician. Acta Biomed. 2007;78(3):233-245.

56. Darba J, Ramirez G, Sicras A, Francoli P, Torvinen S, Sanchez-de la Rosa R. The importance of inhaler devices: the choice of inhaler device may lead to suboptimal adherence in COPD patients. Int JChron Obstruct Pulmon Dis. 2015;10:2335-2345.

57. Ramadan WH, Sarkis AT. Patterns of use of dry powder inhalers versus pressurized metered-dose inhalers devices in adult patients with chronic obstructive pulmonary disease or asthma: an observational comparative study. Chron Respir Dis. 2017;14(3):309-320. 
58. Arora P, Kumar L, Vohra V, et al. Evaluating the technique of using inhalation device in COPD and bronchial asthma patients. Respir Med. 2014;108(7):992-998.

59. Jones TL, Neville DM, Chauhan AJ. The Ellipta ${ }^{\circledR}$ in asthma and chronic obstructive pulmonary disease: device characteristics and patient acceptability. Ther Deliv. 2018;9(3):169-176.

60. Grant AC, Walker R, Hamilton M, Garrill K. The ELLIPTA ${ }^{\circledR}$ dry powder inhaler: design, functionality, in vitro dosing performance and critical task compliance by patients and caregivers. J Aerosol Med Pulm Drug Deliv. 2015;28(6):474-485.

61. Svedsater H, Dale P, Garrill K, Walker R, Woepse MW. Qualitative assessment of attributes and ease of use of the ELLIPTA dry powder inhaler for delivery of maintenance therapy for asthma and COPD. BMC Pulm Med. 2013;13:72.

62. van der Palen J, Thomas M, Chrystyn H, et al. A randomised openlabel cross-over study of inhaler errors, preference and time to achieve correct inhaler use in patients with COPD or asthma: comparison of ELLIPTA with other inhaler devices. NPJ Prim Care Respir Med. 2016;26:16079.

63. Yun Kirby S, Zhu CQ, Kerwin EM, Stanford RH, Georges G. A preference study of two placebo dry powder inhalers in adults with COPD: ELLIPTA $^{\circledR}$ Dry Powder Inhaler (DPI) versus DISKUS ${ }^{\circledR}$ DPI. COPD. 2016;13(2):167-175.
64. Collison KA, Patel P, Preece AF, Stanford RH, Sharma RK, Feldman G. A randomized clinical trial comparing the ELLIPTA and HandiHaler dry powder inhalers in patients with COPD: inhaler-specific attributes and overall patient preference. COPD. 2018;15(1):46-50.

65. Komase Y, Asako A, Kobayashi A, Sharma R. Ease-of-use preference for the ELLIPTA ${ }^{\circledR}$ dry powder inhaler over a commonly used singledose capsule dry powder inhaler by inhalation device-naive Japanese volunteers aged 40 years or older. Int J Chron Obstruct Pulmon Dis. 2014;9:1365-1375.

66. Bremner PR, Birk R, Brealey N, Ismaila AS, Zhu CQ, Lipson DA Single-inhaler fluticasone furoate/umeclidinium/vilanterol versus fluticasone furoate/vilanterol plus umeclidinium using two inhalers for chronic obstructive pulmonary disease: a randomized non-inferiority study. Respir Res. 2018;19(1):19.

67. Brealey N, Gupta A, Renaux J, Mehta R, Allen A, Henderson A. Pharmacokinetics of fluticasone furoate, umeclidinium, and vilanterol as a triple therapy in healthy volunteers. Int J Clin Pharmacol Ther. 2015; 53(9):753-764.
Patient Preference and Adherence

\section{Publish your work in this journal}

Patient Preference and Adherence is an international, peer-reviewed, open access journal that focuses on the growing importance of patient preference and adherence throughout the therapeutic continuum. Patient satisfaction, acceptability, quality of life, compliance, persistence and their role in developing new therapeutic modalities and compounds to optimize

\section{Dovepress}

clinical outcomes for existing disease states are major areas of interest for the journal. This journal has been accepted for indexing on PubMed Central. The manuscript management system is completely online and includes a very quick and fair peer-review system, which is all easy to use. Visit http://www. dovepress.com/testimonials.php to read real quotes from published authors. 